\title{
Steroidogenic acute regulatory protein: its presence and function in brain neurosteroidogenesis*
}

\author{
Hyun Joon Kim, Sang Soo Kang, Gyeong Jae Cho, and Wan Sung Choi \\ Department of Anatomy and Neurobiology, Institute of Health Science, College of Medicine, Gyeongsang National \\ University, Jinju, Korea
}

\begin{abstract}
Summary. Neurosteroids are synthesized de novo and involved in a variety of physiological functions in the central and peripheral nervous systems. Although the steroidogenic acute regulatory protein (StAR) plays an essential role in the steroidogenesis of peripheral endocrine glands, its presence and role in the brain had been previously questioned because of difficulties in detecting it. However, a number of recent studies have confirmed the presence of StAR in rodent and human brains. Moreover, there is evidence suggesting that StAR plays a role in steroidogenesis in the brain, as it does in peripheral endocrine organs. The present review presents data regarding the presence and role of StAR in brain steroidogenesis, demonstrating the essential characteristics of the protein.
\end{abstract}

The term 'neurosteroid' was coined by Baulieu in 1981 to designate a steroid hormone intermediate, dehydroepiandrosterone sulfate (DHEA-S), which was found in the brain at concentrations independent of its plasma levels (Baulieu, 1981). Now it was known that many neurosteroids are synthesized de novo in the central nervous system (CNS) (Paul and Purdy, 1992). Although natural or

Received October 27, 2004

*This research was supported by a grant (M103KV01000203K2201-02000) from the Brain Research Center of the 21st Century Frontier Research Program funded by the MOST of Republic of Korea and partially supported by a grant from the BK 21 Project of Ministry of Education, Republic of Korea.

Address for correspondence: Wan Sung Choi, Ph. D., Department of Anatomy and Neurobiology, Institute of Health Science, College of Medicine, Gyeongsang National University, 92 Chilam-dong, Jinju, 660-751, Korea

Tel: +82-55-751-8716, Fax: +82-55-761-3398

E-mail: choiws@nongae.gsnu.ac.kr synthetic steroids that can alter neuronal membrane excitability are considered as 'neuroactive steroids', irrespective of their origin, neurosteroids are now defined as steroids, the accumulation of which in the CNS and peripheral nervous systems (PNS) occurs independently, at least in part, of any supply by steroidogenic endocrine glands, and which can be synthesized de novo in the nervous system from sterol precursors (Baulieu, 1997).

Neurosteroids are associated with a range of physiological functions including neurotransmission via specific receptors (Majewska, 1992; Monnet et al., 1995), neural growth and differentiation (Bologa et al., 1987), neural plasticity (McEwen et al., 1995, Garcia-Segura et al., 1995), behaviors including memory performance and aggressiveness (Young et al, 1991; Robel et al., 1995), homeostatic effects during stress responses (Broekhoven and Verkes, 2003), and regulatory functions during normal development (Olsen, 1983: Hutchison, 1991). Importantly, the effects of neurosteroids can be mediated without involvement of classic steroid hormone receptors (Majewska et al., 1986).

Steroid hormones are synthesized in the adrenals, gonads, placenta and central nervous system. Organ-specific steroid hormones with different physiological effects are synthesized in each tissue, depending upon the set of enzymes present in it. Regardless of tissue origin, a common feature of all steroid hormones is that they are synthesized from a common precursor, namely cholesterol. Indeed, it is the delivery of cholesterol to the site of its first enzymatic conversion that constitutes the rate-limiting and hormonally acutely-regulated step in steroidogenesis (Karaboyas and Koritz, 1965; Brownie et al., 1972; Simpson, 1979; Crivello and Jefcoate, 1980; Privalle et al., 1983; Jefcoate et al., 1987) - Although the rate-limiting step in steroidogenesis was previously thought to be pregnenolone production (Stone and Hechter, 1954; Karaboyas and Koritz, 1965).

In geater detail, the first step in all steroidogenesis is 
the delivery of cellular cholesterol in the outer mitochondrial membrane to the inner mitochondrial membrane, the site of the cytochrome P450 side chain cleavage enzyme (P450scc) which converts cholesterol to pregnenolone (Lambeth et al., 1987; Privalle et al., 1987). The P450scclinked monooxygenase system is located on the matrix side of the inner mitochondrial membrane. Delivery of cholesterol to $\mathrm{P} 450 \mathrm{scc}$ is an assisted process that requires de novo protein synthesis (Ferguson, 1962, 1963; Garren et al., 1965,1966).

The identity of the protein that assists the translocation of cytoplasmic cholesterol to the mitochondria inner membrane remained a mystery for almost four decades. Of several candidate proteins, the steroidogenic acute regulatory protein (StAR) has been regarded as the most likely one. First identified as a $30 \mathrm{kDa}$ phosphoprotein associated with the mitochondria (Krueger and Orme-Johnson, 1983; Pon et al., 1986; Pon and Orme-Johnson, 1988; Stocco and Kilgore, 1988; Epstein and Orme-Johnson; 1991; Stocco and Sodeman, 1991), StAR was purified, and the gene was cloned and sequenced in 1994 (Clark et al., 1994). Its expression in MA-10 or COS-1 cells resulted in significant increases in steroid hormone synthesis in the absence of hormone stimulation such as the leutenizing hormone and follicle stimulating hormone, suggesting that StAR stimulated cholesterol transport to P450scc (Clark et al., 1994; Sugawara et al., 1995; Lin et al., 1995; Stocco and Clark, 1996). Perhaps the most compelling evidence for a role by StAR in mediating cholesterol transfer and hence regulating steroid hormone biosynthesis was the finding that mutations in the StAR gene result in the potentially lethal condition known as congenital lipoid adrenal hyperplasia (Lin et $a l .$, 1995). This disease is characterized by an almost complete lack of steroid hormone synthesis, and this blockage was found to be at the locus of cholesterol delivery to P450scc. Moreover, StAR 'knockout' mice have been generated and their phenotype is essentially identical to that seen in the human condition (Caron et al., 1997).

In spite of its potential importance, neurosteroid biosynthesis has been poorly understood. Actually, past difficul- ties in identifying StAR in the brain led to doubts as to whether this protein was really involved in brain steroidogenesis. However, recent studies have shown that StAR is present in the mammalian brain, and in this review we summarize the findings of those studies and present evidence indicating a role for StAR in brain steroidogenesis.

\section{StAR expression in rodent brains}

\subsection{Adult brains}

Furukawa et al. (1998) cloned two types of StAR cDNA ( 1.3 and $3.4 \mathrm{~kb}$ ) by library screening from the rat. Using a Northern blot analysis of the rat brain, Kim et al. (2003a) detected StAR mRNA transcripts of 1.6 and $3.6 \mathrm{~kb}$, which were the same sizes as transcripts found in adrenal glands and gonads. The difference in transcript sizes observed using the two methods may be due to polyadenylation (Mizutani et al., 1997).

StAR mRNA transcripts have been identified in the following regions of the adult rat brain: cerebral cortical cells, mitral cells of the olfactory bulb, cells of the caudate putamen, several nuclei in the hypothalamus (the median preoptic, lateral habenular, arcuate hypothalamic and paraventricular nuclei in particular), neuronal cells of CA1, 2, 3 , and dentate gyrus of the hippocampus, cerebellar granule cells, and Purkinje cells (Furukawa et al., 1998; Kim et al., 2003a; Fig. 1). These findings are generally consistent with those of immunohistochemical studies on the localization of the StAR protein in rat and mouse brains (Wehrenberg et al., 2001; Kimoto et al., 2001; King et al., 2002; Sierra et al., 2003). The data from these studies indicate that the StAR expression pattern is similar to that of the P450scc expression pattern (Le Goascogne et al., 1987; Iwahashi et al., 1993; Compagnone et al., 1995). Indeed, StAR and P450scc were shown to co-localize in some hippocampus and cerebellum neurons (Furukawa et al., 1998; Kimoto et al., 2001), strongly demonstrating that StAR may acutely regulate steroidogenesis in the CNS, as has been established in peripheral tissues.

Fig. 1. In situ localization of StAR mRNA in the rat brain (Kim et al., 2003a). A: Schematic localization of StAR mRNA in the rat brain. The symbols, “*”, represent StAR mRNA signals. B: Hippocampus. B-a: Bregma $-4.80 \mathrm{~mm}$. Scale bar: $300 \mu \mathrm{m}$. B-b: Field CA1 of Ammon's horn. Magnified representation of box b in B-a. Scale bars for B-b-e: $60 \mu \mathrm{m}$. B-c: Field CA2 of Ammon's horn. Magnified representation of box c in B-a. (B-d:) Field CA3 of Ammon's horn. Magnified representation of box d in B-a. B-e: Dentate gyrus and polymorph layer. Magnified representation of box e in B-a. C: Cerebellum and pons. C-a: Bregma $-10.52 \mathrm{~mm}$. Scale bar: $300 \mu \mathrm{m}$. C-b: Cerebellar Purkinje cells. Magnified representation of box b in C-a. Scale bar for C-b-e: $60 \mu \mathrm{m}$. C-c: Cerebellar Purkinje cell and cerebellar granular cell layer. Magnified representation of box c in C-a. C-d: Vestibular nucleus. Magnified representation of box c in C-a. C-e: Gigantocellular reticular nucleus. Magnified representation of box e in $\mathrm{C}-\mathrm{a}$. 


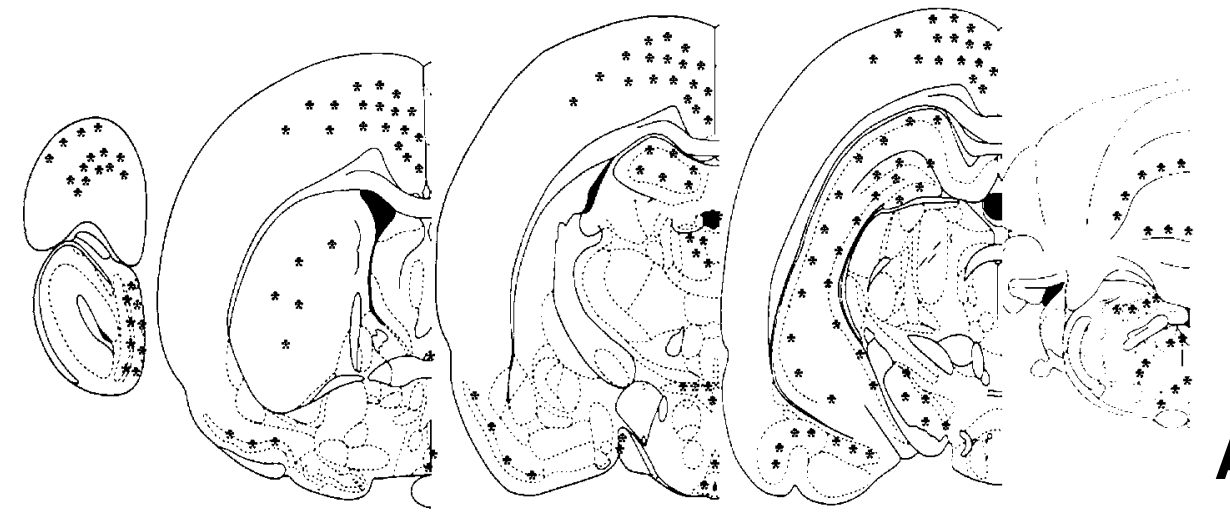

A

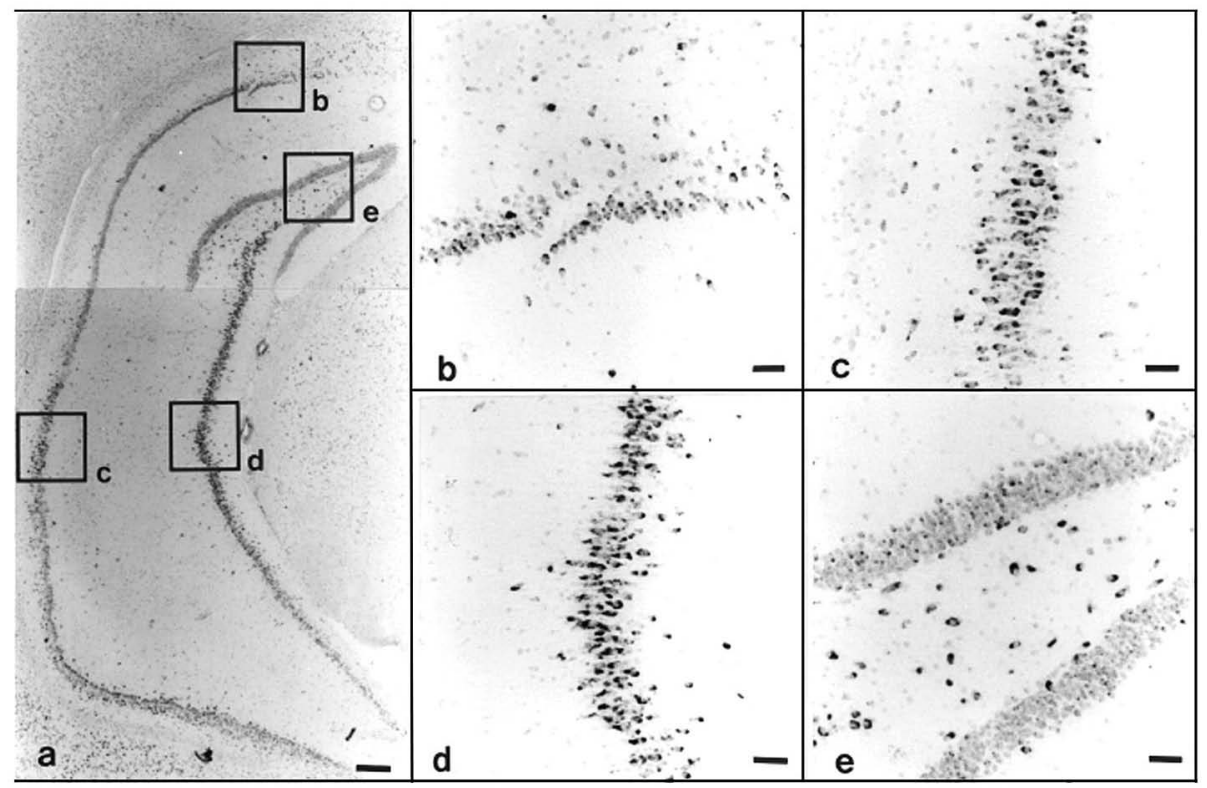

B

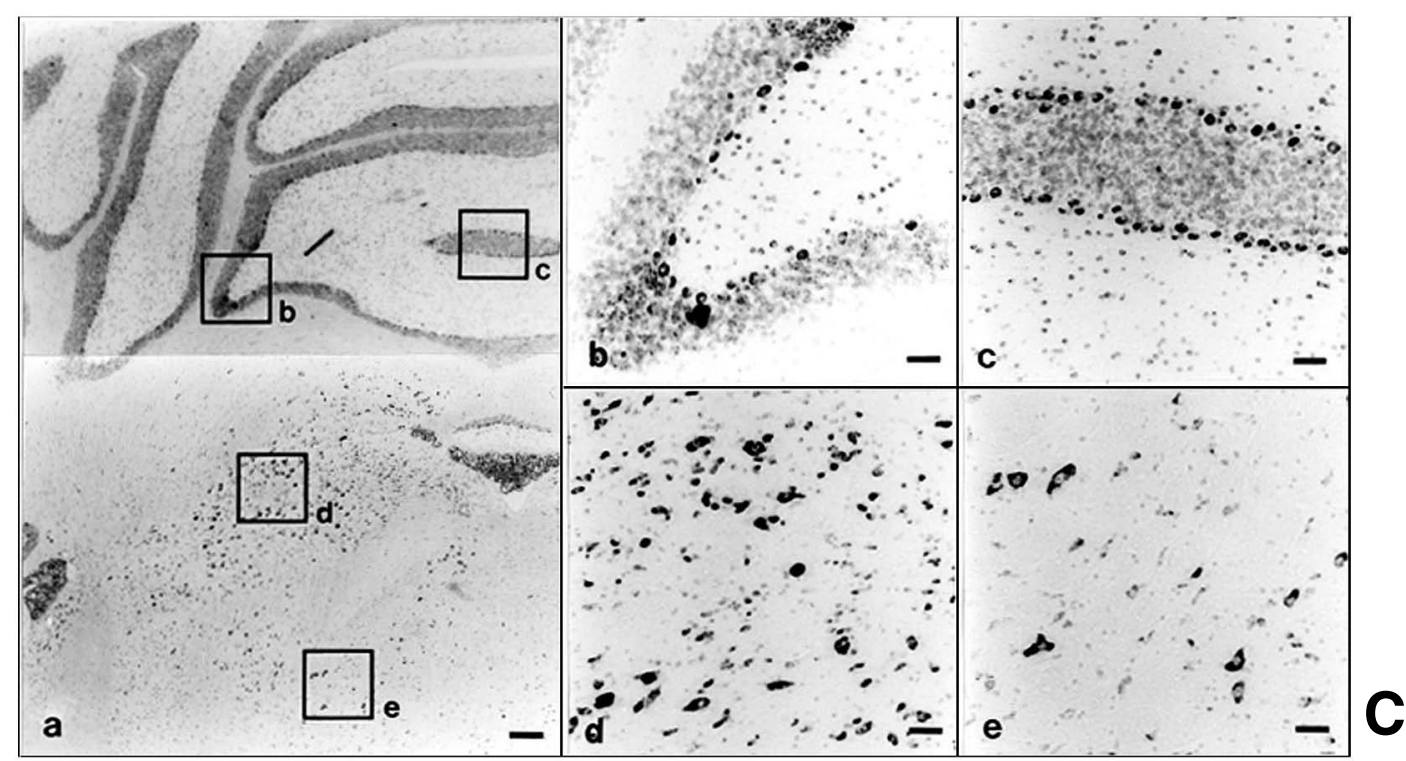

Fig. 1. Legend on the opposite page. 


\subsection{Developing brain}

While the amount of StAR mRNA in the rat brain was found to be much less than that in peripheral endocrine organs, it is expressed from birth and, in general, appears to gradually increase during postnatal development (Kim et al., 2002). StAR mRNA expression has been shown to increase fairly linearly in the hypothalamus from birth to adulthood, while the expression increases in a sigmoidal fashion in the olfactory bulb during the same period of development (Kim et al., 2002). Immunohistochemical studies have shown that the StAR protein first appears in the rat brain on postnatal day 10 , and that the expression then either increases or remains constant until adulthood (Sierra et al., 2003). More recent immunohistochemical studies have shown StAR protein expression in the neonatal mouse brain (King et al., 2004).

The mammalian nervous system is particularly sensitive to steroids during the late fetal and early postnatal periods. At this stage of development, many neuronal and glial cells are undifferentiated, and gonadal steroids influence the survival and maturation of these cells (Arnold and Gorski, 1984; McEwen et al., 1979; McEwen, 1991). Steroid hormones supplied by peripheral steroidogenic organs can cross the blood-brain barrier due to their lipid solubility and can regulate several important brain-neuron functions during development (Fuxe et al., 1981; McEwen, 1991). However, peripheral endocrine organs may not be the sole governor of steroid effects since the developing brain also contains high levels of P450 aromatase, and a significant amount of gonadally derived testosterone is converted to estrogen in the brain (Harada and Yamada, 1992). The aromatization of testosterone is a necessary event in the masculinization of the rodent brain (Naftolin et al., 1975). Besides aromatase, many other steroidogenic enzymes are expressed in the brain from the early embryonic stage through to adulthood (Compagnone and Mellon, 2000).

More interestingly, StAR mRNA and protein have been shown to be expressed in discrete rat brain cell populations during the postnatal period (Kim et al. 2002, Sierra et al. 2003), and it appears that steroids are synthesized de novo in the brain from birth to adulthood. These findings indicate that early postnatal development may also be affected by steroids synthesized de novo in the brain. Furthermore, the increased expression of StAR mRNA in the postnatal period suggests that it might have a role in regulating neurosteroidogenesis associated with neuronal growth and differentiation during postnatal rat brain development (Kim et al., 2002).

\section{StAR expression in human brain and brain tumor}

The human brain is as much a steroidogenic organ as the endocrine glands. Recently, steroidogenic enzymes known to be expressed in adrenal glands were also found to be expressed in the brain (Brown et al., 2000; Yu et al., 2002). Steroid hormones are known to participate in several physiological and pathological processes in the brain, particularly including tumor cell growth (Langeveld et al., 1992; Nygren et al., 1997; Pinski et al., 1993). In addition, steroid receptors are present in the normal human brain and in tumors, and neurosteroidogenesis also occurs de novo (Baulieu, 1981; Weidenfeld and Schiller, 1984; Khalid et al., 1997; Assimakopoulou et al., 1998). Immunohistochemical studies have shown that the StAR protein is expressed in the normal human brain tissue (Inoue et al., 2002, King et al., 2002). More recently, Kim et al. (2003b) reported StAR mRNA and protein expression in the normal human brain and intracranial tumor tissue. These studies showed that StAR mRNA was expressed at very low levels in the white matter of the normal human brain, and was more highly expressed in oligodendrogliomas and malignant glial tumors, suggesting that StAR may play a role in human glioma tumorigenesis. These findings are consistent with those showing that cholesterol is required for glioma cell proliferation (Nygren et al., 1997). Furthermore, the glucocorticoid agonist, dexamethasone, stimulated human glioma cell proliferation, while the glucocorticoid antagonist, RU38486, abolished the effect of dexamethasone (Langeveld et al., 1992, Pinski et al., 1993). Therefore, the steroid hormones that promote tumor cell proliferation can be derived from surrounding micro-vessels in brain tissue, or from the tumor itself through de novo synthesis. In addition, StAR expression was found to be greater in glioblastoma-multiforms, the most malignant form of astrocytoma, compared with anaplastic astrocytomas (Kim et al., 2003b, Fig. 2). Taken together, all this evidence suggests that increased StAR expression might correlate with tumor progression and intratumoral steroidogenesis in malignant astrocytomas (Kim et al., 2003b).

\section{Regulation of StAR expression and its potential roles in the brain}

\subsection{Acute regulation of brain StAR expression}

Clear evidence for the active transcription of StAR under circumstances demanding neurosteroidogenetic activation would strongly support the idea that StAR has a functional 

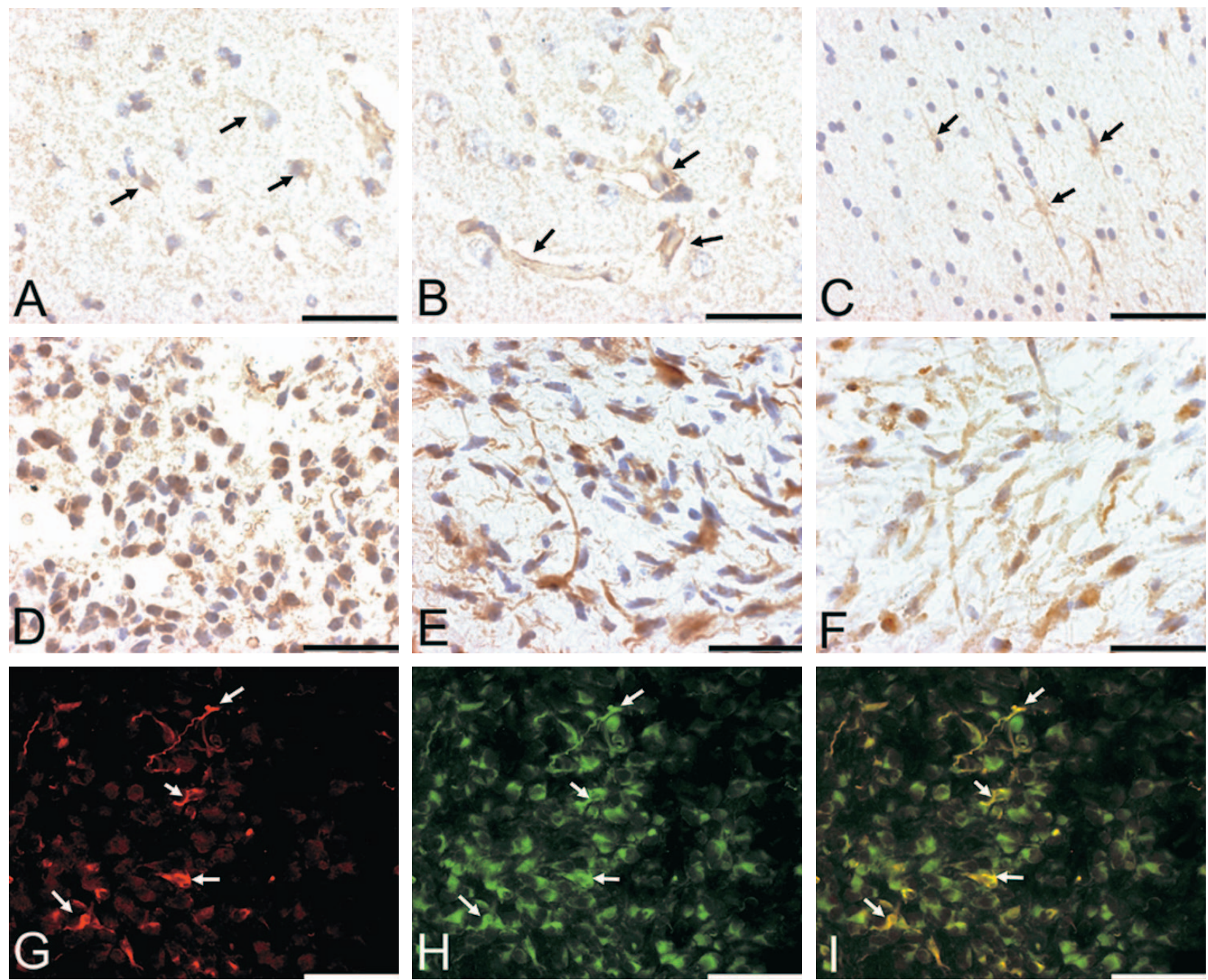

Fig. 2. Immunohistochemistry of StAR in the human brain (Kim et al., 2003b). A and B: Normal human brain gray matter. C: Normal human brain white matter. D: Anaplastic astrocytoma. E and F: Glioblastoma. G-I: Double immunofluorescence of anaplastic astrocytoma using anti-StAR (red) and anti-GFAP (green) antibody. Double positive cells are yellow in I. Scale bars in $\mathrm{A}-\mathrm{I}=50 \mu \mathrm{m}$

significance in the brain. The concentration of brain neurosteroids such as $3 a$-hydroxy-5a-pregnanolone (allopregnanolone) increases in various stress paradigms, including that of acute alcohol administration (Purdy et al., 1991; Barbaccia et al., 1996; VanDoren et al., 2000). VanDoren et al. (2000) reported that elevated brain allopregnanolone levels did not correlate with either plasma corticosterone or progesterone levels or with plasma allopregnanolone levels, and suggested that brain steroids are regulated differently from circulating steroids. Acute alcohol administration can alter levels of brain steroidogenic enzymes either directly or indirectly, and such changes could explain their regulatory roles in coping with environmental changes. In fact, Kim et al. (2003a) showed confirmed rapid changes in the mRNA expression of StAR as well as other steroidogenic enzymes including P450scc, $5 \alpha$-reductase type I, aromatase, $3 \beta$-hydroxysteroid dehydrogenase ( $3 \beta \mathrm{HSD}$ ) and $3 \alpha$-hydroxysteroid dehydrogenase after acute alcohol injection (Fig. 3). De novo neurosteroidogenesis may be anticipated under stressful circumstances in order to maintain brain homeostasis. Indeed, activation of a set of steroidogenic enzymes responsible for de novo synthesis has been reported 

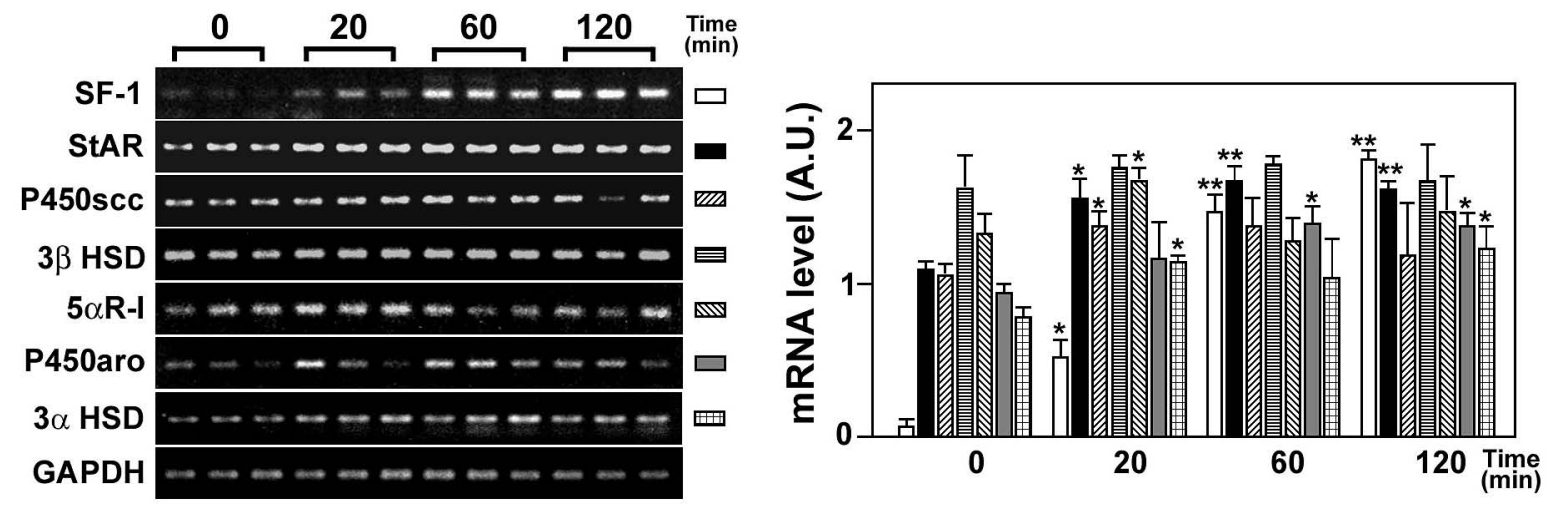

Fig. 3. RT-PCR analysis of steroidogenic enzyme mRNAs after an acute alcohol administration in the frontal cortex (Kim et al., 2003a). The left panels show photographs of PCR products on agarose gels and the right panels show a densitometric analysis of each mRNA levels are presented as arbitrary units (A.U.) that were normalized to the corresponding GAPDH signal. SF-1, steroidogenic factor-1; StAR, steroidogenic acute regulatory protein; $\mathrm{P} 450$ scc, cholesterol side chain cleavage enzyme; $3 \beta \mathrm{HSD}, 3 \beta$-hydroxysteroid dehydrogenase; $5 \alpha \mathrm{R}$-I, $5 \alpha$-reductase; P450aro, aromatase; $3 \alpha$ HSD, $3 \alpha$-hydroxy steroid dehydrogenase. Represented data: mean+S.E.M. ( $n=3) .{ }^{\star} P=0.05$ (vs. '0' time point); ${ }^{\star \star} P=0.01$ (vs. ' 0 ' time point).

(Kim et al., 2003b, Fig. 3). A rapid increase in brain StAR mRNA expression is noteworthy, considering its rate-limiting role in peripheral steroidogenic systems.

\subsection{Constitutive expression of brain StAR in the absence of peripheral endocrine glands}

To our knowledge, the concept of 'neurosteroids' was first proposed on the basis data generated using endocrine organ depletion models (Corpechot et al, 1983). In a recent review, Baulieu commented that the continued presence of steroid compounds several weeks after the surgical removal of adrenal glands and gonads was due to their de novo synthesis in the brain (Baulieu, 1997). Therefore, neurosteroidogenesis is independently maintained in the brain after endocrine gland depletion. Pertinent to the present review, Kim et al. (2003a) showed that StAR mRNA was expressed in various brain regions in the absence of adrenal glands and gonads after surgery. These data indicate that StAR is constitutively expressed in the brain at an extremely low level, and suggest that StAR independently acts to maintain brain steroid levels regardless of the existence of adrenal glands and gonads.

\subsection{Steroidogenic factor-1 and StAR expression in the brain}

Steroidogenic factor-1 (SF-1) is an orphan steroid receptor originally shown to regulate transcription of StAR and essential steroidogenic enzymes in peripheral endocrine organs (Peter and Dubuis, 2000). Since SF-1 and StAR colocalize in the rat hippocampus (Wehrenberg et al., 2001), the transcription of StAR and other steroidogenic enzymes may be regulated by SF-1 in the brain, as an SF-1 an dose in peripheral endocrine glands. Kim et al. (2003a) found that acute alcohol administration resulted in an increase in SF-1 transcription in the frontal cortex and hippocampus, suggesting that SF-1 may activate the transcription of steroidogenic genes including StAR, P450scc and $3 \beta$ HSD. Indeed, they also found increased StAR and P450scc mRNA expression in both regions. However, Zhang et al. (1995) reported that the brain contains an additional factor not found in the adrenal or testis that binds to the rat P450scc promoter and increases its basal and cAMP-mediated transcription. In the hypothalamus, while SF-1 expression did not increase after alcohol injection, StAR and P450scc mRNA expressions were shown to increase (Kim et al., 2003a). These data suggest that StAR and P450scc expressions in the hypothalamus are not regulated by SF-1, even though SF-1 is normally expressed in the ventromedial nucleus and is essential for its development (Ikeda et al., 1994).

In summary, StAR expression appears to be linked to distinct events in brain tissue, and there is strong evidence that it plays a role in the regulation of neurosteroidogenesis (Fig. 4). While it appears that StAR is involved at the start of the neurosteroidogenic pathway, there remain many 


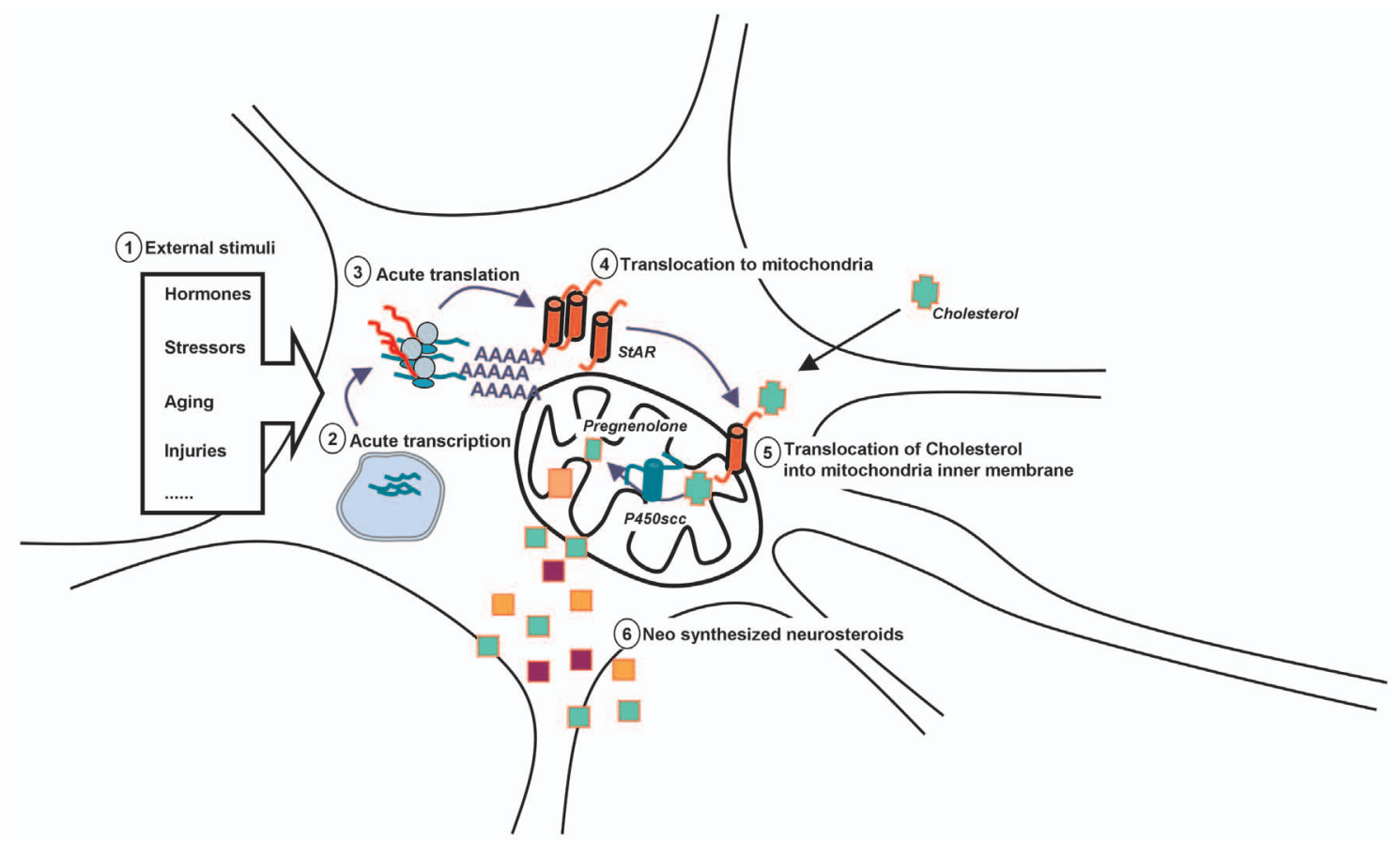

Fig. 4. Schematic diagram of putative mechanism in early stages in brain neurosteroidogenesis. The numerical assigned events on this diagram represent a possible sequence that occurs upon acute neurosteroidogenesis in neural cells.

questions regarding the exact mechanisms underlying the regulation of neurosteroidogenesis by StAR. In addition, little is known of the mechanisms that regulate StAR expression and activity in the brain, particularly in response to externally initiated environmental changes including stress, drugs, and injuries. Such knowledge will serve in the development of strategies for manipulating brain neurosteroidogenesis clinically in order to overcome various neural disorders.

\section{References}

Arnold AP, Gorski RA: Gonadal steroid induction of structural sex differences in the central nervous system. Annu Rev Neurosci 7: 413-742 (1984).

Assimakopoulou M, Sotiropoulou-Bonikou G, Maraziotis $\mathrm{T}$, Varakis J: Does sex steroid receptor status have any prognostic or predictive significance in brain astrocytic tumors? Clin Neuropathol 17: 27-34 (1998).

Barbaccia ML, Roscetti G, Trabucchi M, Mostallino MC, Concas A, Purdy RH, Biggio G: Time-dependent changes in rat brain neuroactive steroid concentrations and GABAA receptor function after acute stress. Neuroendocrinology 63: 166-172 (1996).

Baulieu EE: Steroid hormones in the brain: several mechanisms? In: Steroid hormones regulation of the brain (Fuxe K, Gustafsson JA, Wetterberg L, ed), Pergamon Press, Oxford, UK, 1981 (p. 3-14).

Baulieu EE: Neurosteroids: of the nervous system, by the nervous system, for the nervous system. Recent Prog Horm Res 52: 1-32 (1997).

Bologa L, Sharma J, Roberts E: Dehydroepiandrosterone and its sulfated derivative reduce neuronal death and enhance astrocytic differentiation in brain cell cultures. $J$ Neurosci Res 17: 225-234 (1987).

van Broekhoven F, Verkes RJ: Neurosteroids in depression: a review. Psychopharmacology (Berl) 165: 97-110 (2003).

Brown RC, Cascio C, Papadopoulos V: Pathways of neurosteroid biosynthesis in cell lines from human brain: regulation of dehydroepiandrosterone formation by oxidative stress and beta-amyloid peptide. J Neurochem 74: 847-859 (2000). 
Brownie AC, Simpson ER, Jefcoate CR, Boyd GS, OrmeJohnson WH, Beinert H: Effect of ACTH on cholesterol side-chain cleavage in rat adrenal mitochondria. Biochem Biophys Res Commun 46: 483-490 (1972).

Caron KM, Soo SC, Wetsel WC, Stocco DM, Clark BJ, Parker KL: Targeted disruption of the mouse gene encoding steroidogenic acute regulatory protein provides insights into congenital lipoid adrenal hyperplasia. Proc Natl Acad Sci USA 94: 11540-11545 (1997).

Clark BJ, Wells J, King SR, Stocco DM: The purification, cloning, and expression of a novel luteinizing hormoneinduced mitochondrial protein in MA-10 mouse Leydig tumor cells. Characterization of the steroidogenic acute regulatory protein (StAR). J Biol Chem 269: 2831428322 (1994).

Compagnone NA, Bulfone A, Rubenstein JL, Mellon SH: Expression of the steroidogenic enzyme P450scc in the central and peripheral nervous systems during rodent embryogenesis. Endocrinology 136: 2689-2696 (1995).

Compagnone NA, Mellon SH: Neurosteroids: biosynthesis and function of these novel neuromodulators. Front Neuroendocrinol 21: 1-56 (2000).

Corpechot C, Synguelakis M, Talha S, Axelson M, Sjovall J, Vihko R, Baulieu EE, Robel P: Pregnenolone and its sulfate ester in the rat brain. Brain Res 270: 119-125 (1983).

Crivello JF, Jefcoate CR: Intracellular movement of cholesterol in rat adrenal cells. Kinetics and effects of inhibitors. J Biol Chem 255: 8144-8151 (1980).

Epstein LF, Orme-Johnson NR: Regulation of steroid hormone biosynthesis. Identification of precursors of a phosphoprotein targeted to the mitochondrion in stimulated rat adrenal cortex cells. J Biol Chem 266: 19739-19745 (1991).

Ferguson JJ: Puromycin and adrenal responsiveness to adrenocorticotropic hormone. Biochim Biophys Acta 57: 616-617 (1962).

Ferguson JJ: Protein synthesis and adrenocorticotropin responsiveness. J Biol Chem 238: 2754-2759 (1963).

Furukawa A, Miyatake A, Ohnishi T, Ichikawa Y: Steroidogenic acute regulatory protein (StAR) transcripts constitutively expressed in the adult rat central nervous system: colocalization of StAR, cytochrome P-450SCC (CYP XIA1), and 3beta-hydroxysteroid dehydrogenase in the rat brain. J Neurochem 71: 2231-2238 (1998).

Fuxe K, Kohler C, Agnati LF, Andersson K, Ogren SO, Eneroth P, Perez de la Mora M, Karobath M, Krogsgaard-Larsen P: GABA and benzodiazepine receptors. Studies on their localization in the hippocampus and their interaction with central dopamine neurons in the rat brain. Adv Biochem Psychopharmacol 26: 61-76 (1981).

Garcia-Segura LM, Duenas M, Busiguina S, Naftolin F,
Chowen JA: Gonadal hormone regulation of neuronalglial interactions in the developing neuroendocrine hypothalamus. J Steroid Biochem Mol Biol 53: 293-298 (1995).

Garren LD, Ney RL, Davis WW: Studies on the role of protein synthesis in the regulation of corticosterone production by adrenocorticotropic hormone in vivo. Proc Natl Acad Sci USA 53: 1443-1450 (1965).

Garren LD, Davis WW, Crocco RM, Ney RL: Puromycin analogs: action of adrenocorticotropic hormone and the role of glycogen. Science 152: 1386-1388 (1966).

Harada N, Yamada K: Ontogeny of aromatase messenger ribonucleic acid in mouse brain: fluorometrical quantitation bypolymerase chain reaction. Endocrinology 131: 2306-2312 (1992).

Hutchison JB: Hormonal control of behaviour: steroid action in the brain. Curr Opin Neurobiol 1: 562-570 (1991).

Ikeda Y, Shen WH, Ingraham HA, Parker KL: Developmental expression of mouse steroidogenic factor-1, an essential regulator of the steroid hydroxylases. Mol Endocrinol 8: 654-662 (1994).

Inoue T, Akahira J, Suzuki T, Darnel AD, Kaneko C, Takahashi K, Hatori M, Shirane R, Kumabe T, Kurokawa Y, Satomi S, Sasano H: Progesterone production and actions in the human central nervous system and neurogenic tumors. J Clin Endocrinol Metab 87: 5325-5331 (2002).

Iwahashi K, Kawai Y, Suwaki H, Hosokawa K, Ichikawa Y: A localization study of the cytochrome P-450(21)linked monooxygenase system in adult rat brain. $J$ Steroid Biochem Mol Biol 44: 163-169 (1993).

Jefcoate CR, DiBartolomeis MJ, Williams CA, McNamara $\mathrm{BC}$ : ACTH regulation of cholesterol movement in isolated adrenal cells. J Steroid Biochem 27: 721-729 (1987).

Karaboyas GC, Koritz SB: Identity of the site of action of cAMP and ACTH in corticosteroidogenesis in rat adrenal and beef adrenal cortex slices. Biochemistry 4: 462468 (1965).

Khalid H, Shibata S, Kishikawa M, Yasunaga A, Iseki M, Hiura T: Immunohistochemical analysis of progesterone receptor and Ki-67 labeling index in astrocytic tumors. Cancer 80: 2133-2140 (1997).

Kim HJ, Park CH, Roh GS, Kang SS, Cho GJ, Choi WS: Changes of steroidogenic acute regulatory protein mRNA expression in postnatal rat development. Brain Res Dev Brain Res 139: 247-254 (2002).

Kim HJ, Ha M, Park CH, Park SJ, Youn SM, Kang SS, Cho GJ, Choi WS: StAR and steroidogenic enzyme transcriptional regulation in the rat brain: effects of acute alcohol administration. Brain Res Mol Brain Res 115: 39-49 (2003a). 
Kim HJ, Kim JE, Ha M, Kang SS, Kim JT, Park IS, Paek SH, Jung HW, Kim DG, Cho GJ, Choi WS: Steroidogenic acute regulatory protein expression in the normal human brain and intracranial tumors. Brain Res 978: 245-249 (2003b).

Kimoto T, Tsurugizawa T, Ohta Y, Makino J, Tamura Ho, Hojo Y, Takata N, Kawato S: Neurosteroid synthesis by cytochrome $\mathrm{p} 450$-containing systems localized in the rat brain hippocampal neurons: N-methyl-D-aspartate and calcium-dependent synthesis. Endocrinology 142: 35783589 (2001).

King SR, Manna PR, Ishii T, Syapin PJ, Ginsberg SD, Wilson K, Walsh LP, Parker KL, Stocco DM, Smith RG, Lamb DJ: An essential component in steroid synthesis, the steroidogenic acute regulatory protein, is expressed in discrete regions of the brain. J Neurosci 22: 1061310620 (2002).

King SR, Ginsberg SD, Ishii T, Smith RG, Parker KL, Lamb DJ: The steroidogenic acute regulatory protein is expressed in steroidogenic cells of the day-old brain. Endocrinology 145: 4775-4780 (2004).

Krueger RJ, Orme-Johnson NR: Acute adrenocorticotropic hormone stimulation of adrenal corticosteroidogenesis. Discovery of a rapidly induced protein. J Biol Chem 258: 10159-10167 (1983).

Lambeth JD, Xu XX, Glover M: Cholesterol sulfate inhibits adrenal mitochondrial cholesterol side chain cleavage at a site distinct from cytochrome P-450scc. Evidence for an intramitochondrial cholesterol translocator. J Biol Chem 262: 9181-9188 (1987).

Langeveld CH, van Waas MP, Stoof JC, Sutanto W, de Kloet ER, Wolbers JG, Heimans JJ: Implication of glucocorticoid receptors in the stimulation of human glioma cell proliferation by dexamethasone. J Neurosci Res 31: 524-531 (1992).

Le Goascogne C, Robel P, Gouezou M, Sananes N, Baulieu EE, Waterman M: Neurosteroids: cytochrome P-450scc in rat brain. Science 237: 1212-1215 (1987).

Lin D, Sugawara T, Strauss JF 3rd, Clark BJ, Stocco DM, Saenger P, Rogol A, Miller WL: Role of steroidogenic acute regulatory protein in adrenal and gonadal steroidogenesis. Science 267: 1828-1831 (1995).

Majewska MD, Harrison NL, Schwartz RD, Barker JL, Paul SM: Steroid hormone metabolites are barbituratelike modulators of the GABA receptor. Science 232 1004-1007. (1986).

Majewska MD: Neurosteroids: endogenous bimodal modulators of the $\mathrm{GABA}_{\mathrm{A}}$ receptor. Mechanism of action and physiological significance. Prog Neurobiol 38: 379-395 (1992).

McEwen BS, Davis PG, Parsons B, Pfaff DW: The brain as a target for steroid hormone action. Annu Rev Neurosci
2: 65-112 (1979).

McEwen BS, Gould E, Orchinik M, Weiland NG, Woolley CS: Oestrogens and the structural and functional plasticity of neurons: implications for memory, ageing and neurodegenerative processes. Ciba Found Symp 191:52-66; discussion 66-73 (1995).

McEwen BS: Non-genomic and genomic effects of steroids on neural activity. Trends Pharmacol Sci 12: 141-147 (1991).

Mizutani T, Sonoda Y, Minegishi T, Wakabayashi K, Miyamoto K: Molecular cloning, characterization and cellular distribution of rat steroidogenic acute regulatory protein (StAR) in the ovary. Life Sci 61: 1497-506 (1997).

Monnet FP, Mahe V, Robel P, Baulieu EE: Neurosteroids, via sigma receptors, modulate the $[3 \mathrm{H}]$ norepinephrine release evoked by N-methyl-D-aspartate in the rat hippocampus. Proc Natl Acad Sci USA 92: 3774-3778 (1995).

Naftolin F, Ryan KJ, Davies IJ, Reddy VV, Flores F, Petro Z, Kuhn M, White RJ, TakaokaY, Wolin L: The formation of estrogens by central neuroendocrine tissues. Recent Prog Horm Res 31: 295-319 (1975).

Nygren C, von Holst H, Mansson JE, Fredman P: Increased levels of cholesterol esters in glioma tissue and surrounding areas of human brain. Br J Neurosurg 11: 216-220 (1997).

Olsen KL: Genetic determinants of sexual differentiation. In: Hormones and behavior in higher vertebrates (Balthazart J, Prove E, and Gilles R, ed), Springer-Verlag, New York, 1983 (p.138-158)

Paul SM, Purdy RH: Neuroactive steroids. FASEB J 6(6): 2311-2322 (1992).

Peter M, Dubuis JM: Transcription factors as regulators of steroidogenic P-450 enzymes. Eur J Clin Invest 30 Suppl 3:14-20 (2000).

Pinski J, Halmos G, Shirahige Y, Wittliff JL, Schally AV: Inhibition of growth of the human malignant glioma cell line (U87MG) by the steroid hormone antagonist RU486. J Clin Endocrinol Metab 77: 1388-1392 (1993).

Pon LA, Orme-Johnson NR: Acute stimulation of corpus luteum cells by gonadotrophin or adenosine 3', 5' monophosphate causes accumulation of a phosphoprotein concurrent with acceleration of steroid synthesis. Endocrinology 123: 1942-1948 (1988).

Pon LA, Hartigan JA, Orme-Johnson NR: Acute ACTH regulation of adrenal corticosteroid biosynthesis. Rapid accumulation of a phosphoprotein. J Biol Chem 261: 13309-13316 (1986).

Privalle CT, Crivello JF, Jefcoate CR: Regulation of intramitochondrial cholesterol transfer to side-chain cleavage cytochrome P-450 in rat adrenal gland. Proc Natl Acad Sci USA 80: 702-706 (1983). 
Privalle CT, McNamara BC, Dhariwal MS, Jefcoate CR: ACTH control of cholesterol side-chain cleavage at adrenal mitochondrial cytochrome P-450scc. Regulation of intramitochondrial cholesterol transfer. Mol Cell Endocrinol 53: 87-101 (1987).

Purdy RH, Morrow AL, Moore PH Jr, Paul SM: Stressinduced elevations of gamma-aminobutyric acid type A receptor-active steroids in the rat brain. Proc Natl Acad Sci USA 88: 4553-4557 (1991).

Robel P, Young J, Corpechot C, Mayo W, Perche F, Haug M, Simon H, Baulieu EE: Biosynthesis and assay of neurosteroids in rats and mice: functional correlates. $J$ Steroid Biochem Mol Biol 53: 355-360 (1995).

Sierra A, Lavaque E, Perez-Martin M, Azcoitia I, Hales DB, Garcia-Segura LM: Steroidogenic acute regulatory protein in the rat brain: cellular distribution, developmental regulation and overexpression after injury. Eur $J$ Neurosci 18: 1458-1467 (2003).

Simpson ER: Cholesterol side-chain cleavage, cytochrome P450, and the control of steroidogenesis. Mol Cell Endocrinol 13: 213-227 (1979).

Stocco DM, Clark BJ: Role of the steroidogenic acute regulatory protein (StAR) in steroidogenesis. Biochem Pharmacol 51: 197-205 (1996).

Stocco DM, Kilgore MW: Induction of mitochondrial proteins in MA-10 Leydig tumour cells with human choriogonadotropin. Biochem J 249: 95-103 (1988).

Stocco DM, Sodeman TC: The 30-kDa mitochondrial proteins induced by hormone stimulation in MA-10 mouse Leydig tumor cells are processed from larger precursors. J Biol Chem 266: 19731-19738 (1991).

Stone D, Hechter O: Studies on ACTH action in perfused bovine adrenals: site of action of ACTH in corticosteroidogenesis. Arch Biochem Biophys 51: 457-469 (1954).
Sugawara T, Holt JA, Driscoll D, Strauss JF 3rd, Lin D, Miller WL, Patterson D, Clancy KP, Hart IM, Clark BJ, Stocco DM: Human steroidogenic acute regulatory protein: functional activity in COS-1 cells, tissue-specific expression, and mapping of the structural gene to 8p11.2 and a pseudogene to chromosome 13. Proc Natl Acad Sci USA 92: 4778-4782 (1995).

VanDoren MJ, Matthews DB, Janis GC, Grobin AC, Devaud LL, Morrow AL: Neuroactive steroid 3alphahydroxy-5alpha-pregnan-20-one modulates electrophysiological and behavioral actions of ethanol. J Neurosci 20: 1982-1989 (2000).

Wehrenberg U, Prange-Kiel J, Rune GM: Steroidogenic factor-1 expression in marmoset and rat hippocampus: co-localization with StAR and aromatase. J Neurochem 76: 1879-1886 (2001).

Weidenfeld J, Schiller H: Metabolism of steroids by human brain tumors. Clin Neuropharmacol 7: 395-397 (1984).

Young J, Corpechot C, Haug M, Gobaille S, Baulieu EE, Robel P: Suppressive effects of dehydroepiandrosterone and 3 beta-methyl-androst-5-en-17-one on attack towards lactating female intruders by castrated male mice. II. Brain neurosteroids. Biochem Biophys Res Commun 174: 892-897 (1991).

Yu L, Romero DG, Gomez-Sanchez CE, Gomez-Sanchez EP: Steroidogenic enzyme gene expression in the human brain. Mol Cell Endocrinol 190: 9-17 (2002).

Zhang P, Rodriguez H, Mellon SH: Transcriptional regulation of P450scc gene expression in neural and steroidogenic cells: implications for regulation of neurosteroidogenesis. Mol Endocrinol 9: 1571-1582 (1995). 